\title{
Leptolejeunea E Rhaphidolejeunea (LEJEUNEACEAE) NA ESTAÇÃo CIENTÍFICA FERREIRA PENNA, PARÁ, BRASIL.
}

\author{
Anna Luiza ILKIU-BORGES ${ }^{1}$, Regina Célia Lobato LISBOA ${ }^{1}$
}

RESUMO - Em um inventário da família Lejeuneaceae (Hepaticae) na Estação Científica Ferreira Penna, município de Melgaço, Pará, foi observada a ocorrência de Leptolejeunea elliptica (Lehm. \& Lindenb.) Schiffn., Leptolejeunea tridentata Bischler e Rhaphidolejeunea polyrhiza (Nees) Bischler. Leptolejeunea tridentata é uma nova ocorrência para o Brasil. Todas as espécies são descritas e ilustradas, com comentários adicionais. Uma chave artificial para a separação das mesmas é apresentada.

Palavras-chave: brioflora, Lejeuneaceae, hepáticas, fitogeografia, Pará.

Leptolejeunea and Rhaphidolejeunea (Lejeuneaceae) of Ferreira PenaScientific Station, Pará State, Brazil.

ABSTRACT - A survey of the Lejeuneaceae (Hepaticae) family was performed at Ferreira Penna Research Station, Melgaço municipality, Pará, where was observed Leptolejeunea eliptica (Lehm. \& Lindenb.) Schiffn., Leptolejeunea tridentata Bischler and Rhaphidolejeunea polyrhiza (Nees) Bischler. Leptolejeunea tridentata is a new occurrence to Brazil. The species are described and illustrated and na artificial key is presented to separate them, as well as additional commentaries.

Key-words: bryoflora; Lejeuneaceae; liverworts; phytogeography; Pará.

\section{Introdução}

Em continuidade ao inventário de Lejeuneaceae (Hepaticae) na Estação Científica Ferreira Penna, município de Melgaço, Pará, foi feito o estudo dos gêneros Leptolejeunea (Spruce) Steph. e Rhaphidolejeunea Herzog, pertencentes à subfamília Lejeuneoideae Massal. e à tribo Lejeunea Schuster.

Leptolejeunea é um gênero pantropical. Inicialmente, foram relacionadas seis espécies para a América tropical por Spruce (1985), ainda como Lejeunea e subgênero Lepto-lejeunea, o qual foi elevado à categoria de gênero por Stephani (1890). Este gênero é considerado estreitamente relacionado a Drepanolejeunea Steph,, cujas semelhanças e diferenças são discutidas por Evans (1902) e principalmente por Bischler (1969), que faz uma revisão do gênero Leptolejeunea na América, apresentando descrição, ilustração e diversos comentários para 12 espécies. Outro gênero considerado muito semelhante a Lepiolejeunea é Rhaphidolejeunea Herzog (Bischler, 1968), cujas primeiras espécies derivaram de Leptolejeunea. Rhaphidolejeunea apresenta uma distribuição asiático-americana e é representado no continente americano pela espécie Rhaphidolejeunea polyrhiza (Nees) Bischler. Um estudo aprofundado sobre este gênero foi realizado por Bischler (1968), que discute, descreve e ilustra 8 espécies. O objetivo deste trabalho é

'MCT / Museu Paraense Emilio Goeldi - Coordenação de Botânica. C.P. 399, CEP 66040-170, Belém - PA. 
ampliar a distribuição geográfica de espécies dos gêneros Leptolejeunea e Rhaphidolejeunea, contribuindo para o conhecimento de Lejeuneaceae na Estação Científica Ferreira Penna, assim como no estado do Pará.

\section{Material e Métodos}

O material estudado é proveniente de coletas realizadas na Estação Científica Ferreira Penna (ECFPn), localizada na Floresta Nacional de Caxiuanã, município de Melgaço, estado do Pará, Brasil.

A coleta do material seguiu o método adotado por Yano (1984a) e Lisboa (1993).

As espécies foram classificadas de acordo com o tipo de substrato onde foram coletadas, segundo Robbins (1952).

A identificação taxonômica foi feita através de chaves de identificação em bibliografia especializada e/ou comparação com espécies identificadas por especialistas.

$\mathrm{O}$ material estudado encontra-se depositado no Herbário "João Murça Pires" (MG), do Museu Paraense Emílio Goeldi. Os Tipos das espécies não foram examinados. As abreviaturas dos herbários depositários dos Tipos estão de acordo com Iwatsuki et al. (1976).

\section{Resultados Discussões}

Os gêneros Leptolejeunea e Rhaphidolejeunea agrupam espécies pequenas, com filídios elípticos com um ápice arredondado e ocelos seriados, entretanto diferem quanto aos lóbulos que se apresentam bordeados por células maiores em Leptolejeunea, com um dente curto e obtuso, além da ausência de inovações no gineceu, enquanto em Rhaphidolejeunea a borda diferenciada está ausente, o dente do lóbulo é longo e falcado e observa-se uma inovação no gineceu (Bischler, 1968 e 1969).

Foram identificadas duas espécies de Leptolejeunea e uma de Rhaphidolejeunea para a área da Estação Científica Ferreira Penna, apresentadas a seguir.

\section{Leptolejeunea (Spruce) Stephani}

1. Filídios com margens levemente crenuladas, às vezes anguloso-denteadas; gametófitos medindo 4-8x0,7-0,8mm; sempre apresenta 1 ocelo basal e mais (1)2-3 ocelos laminares; anfigastros com lobos amplamente divergentes ou formando um sinus levemente convexo.......................... elliptica

1'. Filídios com margens denteadas, com 3 dentes distintos, podendo apresentar, às vezes, um dos dentes menor, com uma célula projetada; gametófitos $2-3 \times 0,4-0,5 \mathrm{~mm}$; apenas 2 ocelos por lobo, separados por 3-4 células; anfigastros com lobos sempre eretos, formando um sinus profundamente convexo..........L. tridentata

\section{Leptolejeunea}

elliptica (Lehmann \& Lindenberg) Schiffner in Engler \& Plantl., Nat. Pflanzenfam., 1(3): 126. 1893 (Fig. 1).

Basiônimo: Jungermannia elliptica Lehmann \& Lindenberg in Lehmann, Pugillus, 5: 13. 1833.

Tipo: Suriname. S. loc., sine 

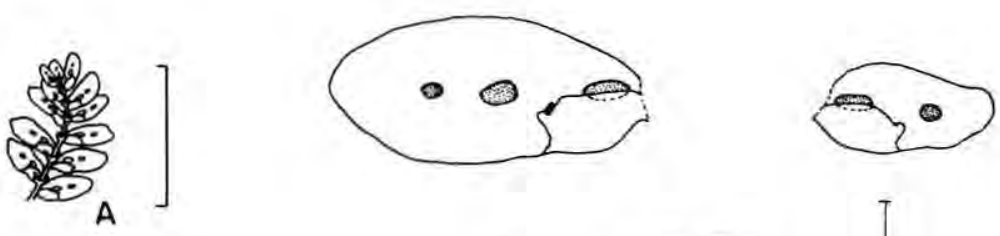

B
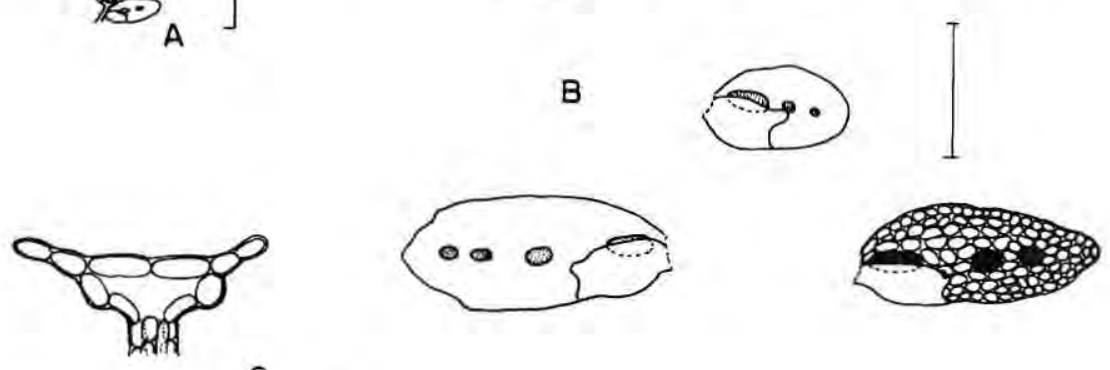

C
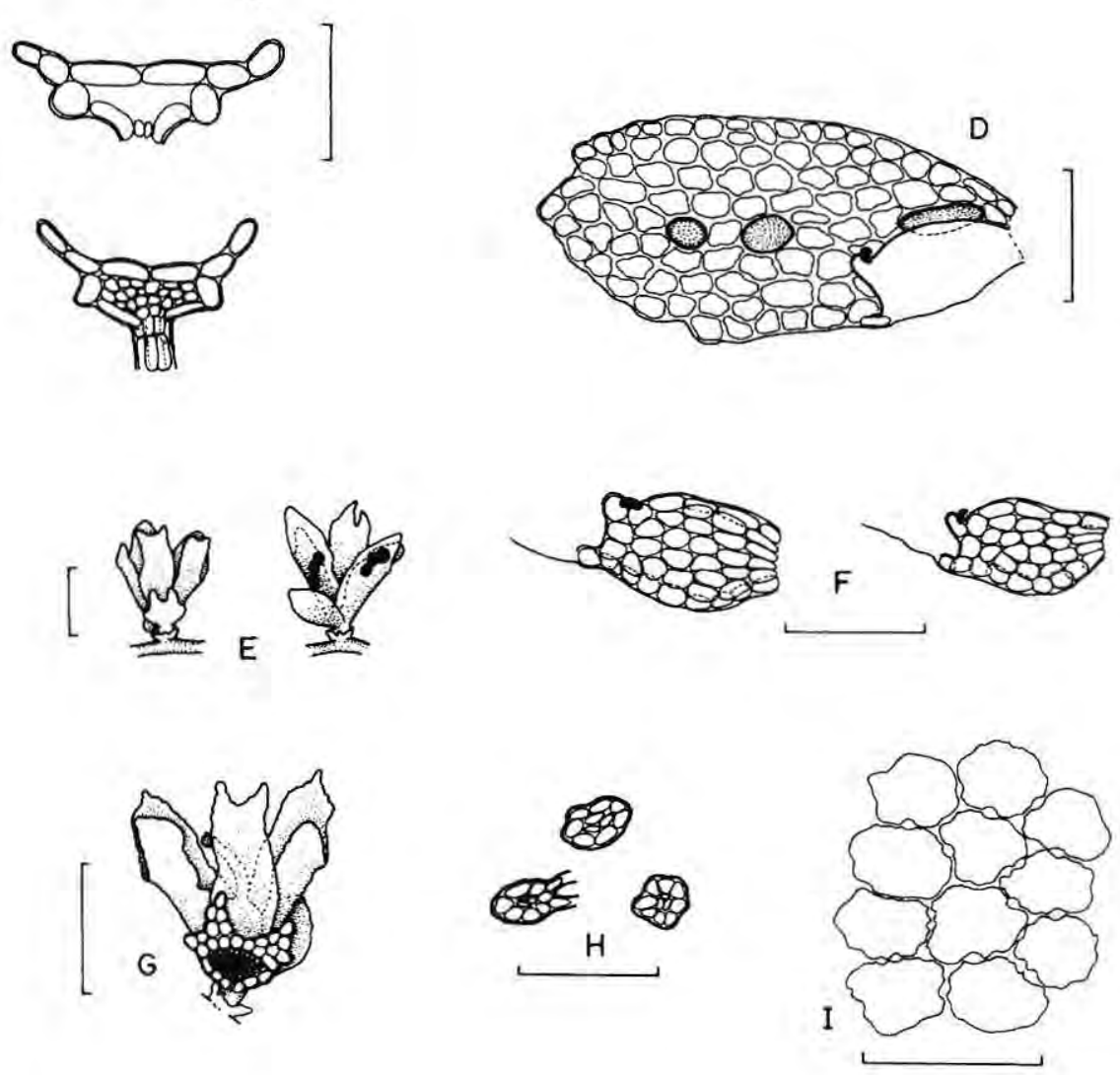

Figura 1. Leptolejeunea elliptica (A-I) A. hábito, vista ventral; B. 5 exemplos de filidios; C. anfigastros; D. filidio em detalhe; E. gineceu em vista ventral e dorsal; F. lóbulos com papilas hialinas Destacadas; $G$. gineceu em detalhe; $H$. secção transversal do caulídio; I. células da região mediana do filidio (R. Lisboa, A. L. Ilkiu-Borges \& M. Silva, 6035); Escalas: A = 1mm; B, E e $\mathrm{G}=200 \mu \mathrm{m} ; \mathrm{C}, \mathrm{D}, \mathrm{F}$, e $\mathrm{H}=100 \mu \mathrm{m} ; \mathrm{I}=50 \mu \mathrm{m}$ (Desenho: Anna Luiza Ilkiu-Borges). 
nom. mis. Kunze, s. d., s. col., s. n. (Holótipo, W).

Gametófitos amarelados a castanhos (secos), pequenos, delicados, prostrados, 4-8mm de comprimento e $0,7-0,8 \mathrm{~mm}$ de largura. Caulídio em secção transversal com $7-8$ células epidérmicas circundando 3-4 células medulares menores, merófito ventral de 2 células de largura. Filídios elípticos a elíptico-ovalados, involutos quando secos, distantes a contíguos, 210 $430 \mu \mathrm{m}$ de comprimento e $120-210 \mu \mathrm{m}$ de largura, obliquamente dispostos no caulídio, ápice mais ou menos agudo a arredondado, margens levemente crenuladas, às vezes angulosodenteadas, 2-4 ocelos dispostos em uma fila interrompida por células não oceladas, iniciam na base e seguem em direção ao ápice do lobo, tornamse menores à medida que se distanciam da base, ocelo suprabasal $45-60 \times 20-25 \mu \mathrm{m}$, maior que as células adjacentes, células do lobo isodiamétricas a levemente alongadas próximo à base, com $20-30 \times 15-20 \mu \mathrm{m}$, células marginais levemente menores, trigônios conspícuos, 4-5 espessamentos intercelulares. Lóbulos oblongos, inflados, $100-130 \mu \mathrm{m}$ de comprimento e $70-80 \mu \mathrm{m}$ de largura, quilha do lóbulo levemente arqueada, margem livre plana, dente apical formado por uma célula, arredondado, papila hialina na base proximal do dente apical em um sinus lunulado. Anfigastros distantes, bífidos, lobos divergentes, filiformes, formados por duas células enfileiradas, separados por duas células alongadas, lâmina conspicuamente bordeada por 6 células
(2 no ápice, 2 em cada lado) que cercam inúmeras pequenas células, potencialmente rizoidiferas, $90-110 \mu \mathrm{m}$ de comprimento e $100-110 \mu \mathrm{m}$ de largura, $(120-170 \mu \mathrm{m}$ de um ápice a outro dos lobos), base abruptamente estreitada, pois as células inferiores da margem convergem para a linha de inserção, mais ou menos reta. Androceu não observado. Gineceu em curtos ramos especializados, sem inovações, brácteas com lobos elípticos-lanceolados, com 3 ocelos enfileirados, ápice agudo, lóbulos lanceolados, bractéola mais ou menos retangular, tão longa quanto as brácteas, bem maior que um anfigastro, bífida, lobos divergentes, às vezes coniventes, margens das brácteas e bractéolas levemente crenuladas. Perianto e esporófito não observados.

\section{Distribuição geográfica:} Ocorre na Bolívia, Brasil, Colômbia, Costa Rica, Cuba, Equador, EUA (Bahamas, Flórida), Filipinas, Galápagos (Equador), Guadaloupe, Guatemala, Guiana Francesa, Guiana, Honduras, Jamaica, Martinica, México, Nova Zelândia, Panamá, Peru, Porto Rico, Suriname, Trinidad e Venezuela (Bischler, 1969; Lücking, 1995). No Brasil é citada para os estados do AM, ES, MG, PA, PE, PR, RJ, RR, SC e SP (Yano, 1984b, 1989 e 1995). Já foi mencionada para a ECFPn, por Lisboa \& Nazaré (1997).

Discussão: Essa é uma espécie preferencialmente epífila em florestas úmidas da região tropical, de acordo com Bischler (1969). L. elliptica apresenta grande variação morfológica, apresentando filídios elípticos, ovalados 
ou obovados, simétricos ou assimétricos, com as margens inteiras a crenuladas, raramente com dentículos. Essa última característica às vezes ocorre nos espécimes encontrados em Caxiuanã.

Material examinado: Melgaço (PA), ECFPn: margem esquerda do rio Curuá, várzea, sobre folhas vivas, 2.XII.1997, A. L. Ilkiu-Borges, O. Nascimento \& M. Silva, 883; idem, terra firme, sobre folhas vivas de planta jovem no sub-bosque, 5.XII.1997, A. L. Ilkiu-Borges, O. Nascimento \& M. Silva, 919; igarapé Laranjal, caminho para o laranjal, mata de capoeira, sobre folhas de palmeira, 7.XII.1997, A. L. Ilkiu-Borges, 1007; margem esquerda do rio Curuá, várzea, sobre tronco de Macrolobium sp., 8.XII.1997, A. L. Ilkiu-Borges, O. Nascimento \& M. Silva, 1107; idem, sobre folhas vivas, 8.XII.1997, A. L. Ilkiu-Borges, O. Nascimento \& $\mathrm{M}$. Silva, 1134; igarapé Grande, várzea, muito úmida, sobre plântula viva e folhas, 17.I.1993, R. Lisboa, 2310; igarapé Retiro, picada para o inventário 12, terra firme, sobre folha de palmeira, 1.XI.1996, R. Lisboa, A. L. Ilkiu-Borges \& M. Silva, 6033; idem, 1.XI.1996, R. Lisboa, A. L. IlkiuBorges \& M. Silva, 6035; idem, sobre cipó, 1.XI.1996, R. Lisboa, A. L. IlkiuBorges \& M. Silva, 6049.

\section{Leptolejeunea tridentata} Bischler in Nova Hedwigia, 17: 335. 1969 (Fig. 2).

Tipo: Colombia. Chocó, au bord de la route Quibdó-Tutunendo, $80 \mathrm{~m}$., 17.IV.1957, Bischler 188 (Holótipo, PC).

Gametófitos amarelados a castanhos (secos), muito pequenos, delicados, prostrados, $2-3 \mathrm{~mm}$ de comprimento e $0,4-0,5 \mathrm{~mm}$ de largura. Caulídio em secção transversal com 8 células epidérmicas circundando 3 células medulares menores, merófito ventral de 2 células de largura. Filídios elíptico-obovados, involutos quando secos, distantes a contíguos, 190$220 \mu \mathrm{m}$ de comprimento e $90-100 \mu \mathrm{m}$ de largura, sempre com 3 dentes, raramente mais, o primeiro dente localizado na margem antical, a $2 / 3$ do comprimento, 2-3 células de comprimento, o segundo dente no ápice, 1-2 células de comprimento e o terceiro dente subapical ou na margem postical, com 1 célula de comprimento, podendo estar reduzido a apenas 1 célula projetada, 2 ocelos dispostos em uma fila interrompida por células não oceladas, o primeiro suprabasal, mede 40-55x25-35 $\mu \mathrm{m}$, três vezes o tamanho das células adjacentes, o segundo ocelo está situado a $2 / 3$ do comprimento do lobo e possui o mesmo tamanho das células adjacentes, células do lobo isodiamétricas a levemente alongadas, $15-25 \times 10-15 \mu \mathrm{m}$, trigônios conspícuos, 4-5 espessamentos intercelulares. Lóbulos oblongos, inflados na base, 90 $100 \mu \mathrm{m}$ de comprimento e $50-55 \mu \mathrm{m}$ de largura, quilha do lóbulo levemente arqueada, margem livre plana, dente apical arredondado, formado por uma célula levemente alongada, papila hialina na base proximal do dente apical em um sinus lunulado. Anfigastros distantes, bífidos, lobos eretos, filiformes, formados por duas células enfileiradas, separados por duas células alongadas, lâmina conspicuamente 

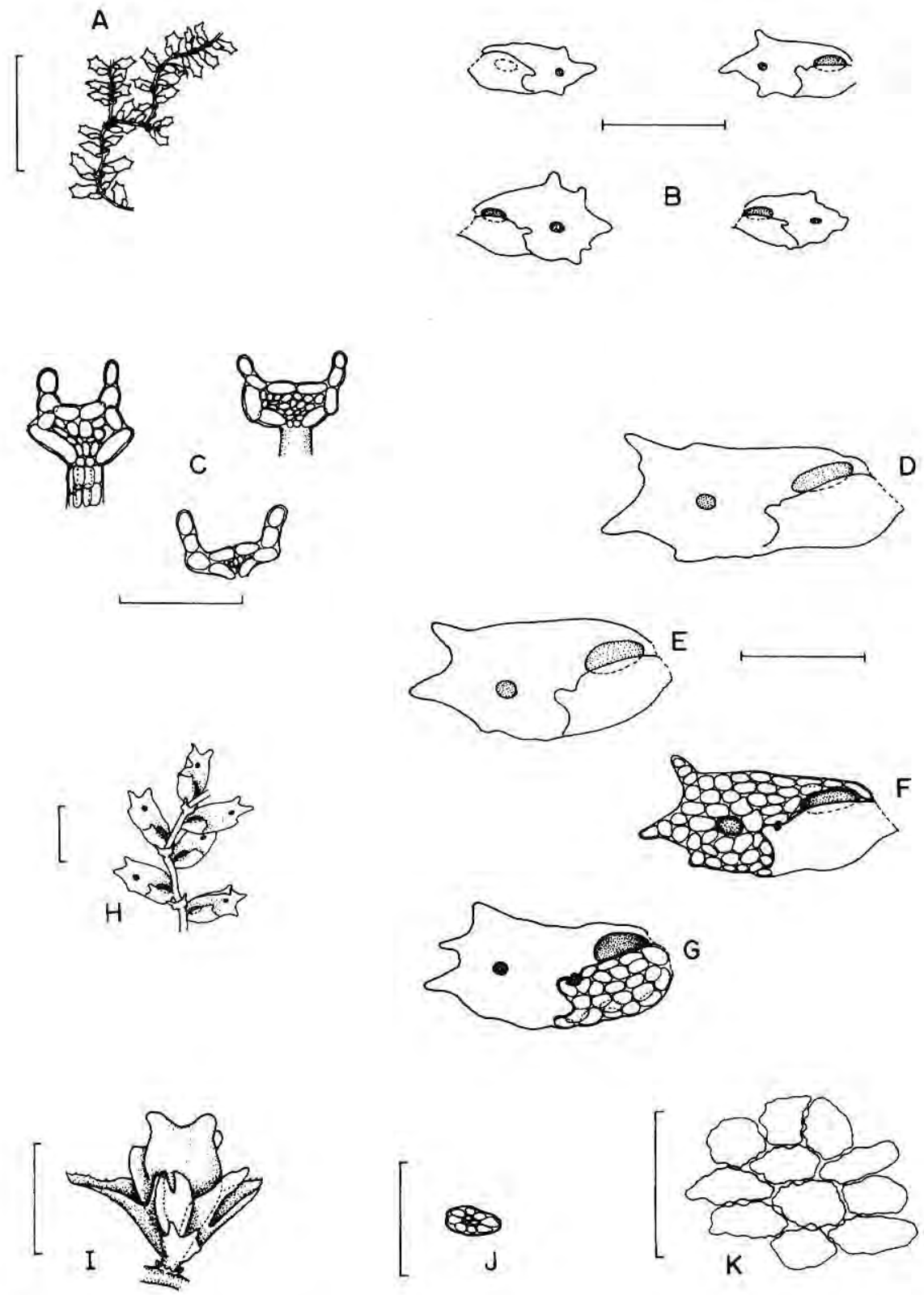

Figura 2. Leptolejeunea tridentata (A-K) A. hábito, vista ventral; B. filídios; C. anfigastros; D, E, F e G. filídios em detalhe; H. hábito em detalhe; I. perianto; J. secção transversal do caulídio; K. células da região mediana do filídio (A. L. Ilkiu-Borges, O. Nascimento \& M. Silva, 883); Escalas: $\mathrm{A}=1 \mathrm{~mm}$; B, H e I $=200 \mu \mathrm{m} ; \mathrm{C}, \mathrm{D}, \mathrm{E}, \mathrm{F}, \mathrm{G}$ e J $=100 \mu \mathrm{m} ; \mathrm{K}=50 \mu \mathrm{m}$ (Desenho: Anna Luiza Ilkiu-Borges). 
bordeada por seis células (duas no ápice e duas em cada lado) que cercam inúmeras pequenas células potencialmente rizoidíferas, $70-90 \mu \mathrm{m}$ de comprimento (até o ápice dos lobos) e $70-80 \mu \mathrm{m}$ de largura, base abruptamente estreitada, pois as células inferiores da margem convergem para a linha de inserção, mais ou menos reta. Androceu não observado. Gineceu em curtos ramos especializados, sem inovações, brácteas com lobos obovadolanceolados, ápice agudo, lóbulos lanceolados, bractéola obovada, bem maior que o anfigastro, bífida, lobos eretos, sinus em forma de "V", cobre $1 / 2$ do perianto, margens das brácteas e bractéolas crenuladas e crenuladodenticuladas. Periantos obovados, inflados, com 5 quilhas, que se estendem para cima, infladas, formando pequenos cornos arredondados, superfície lisa, $350 \mu \mathrm{m}$ de comprimento e $140 \mu \mathrm{m}$ de largura, rostro curto, inconspícuo. Esporófito não observado.

Distribuição geográfica: Está distribuida pela América Meridional, segundo Bischler (1969). Aqui é feita a primeira citação para o Brasil.

Discussão: Como explica o epíteto dessa espécie, L. tridentada apresenta como caracteristica mais marcante, a constante presença de três dentes por filídio, podendo às vezes apresentar um dos dentes menor, com uma célula projetada, em algum filídio no gametófito, porém estão sempre presentes;. Apenas uma vez foi observado um filídio com mais de três dentes, entretanto dois como células projetadas. Observou-se, por este motivo, uma leve semelhança $\operatorname{com} L$. serratifolia Schiffner, que apresenta as margens dos filídios crenuladas a denteadas, destacando-se 4-8 células projetadas, entretanto esta característica é constante nos filídios, além disso, L. serratifolia apresenta apenas um ocelo por filídio, enquanto $L$. tridentada apresenta três dentes definidos e dois ocelos por filídio. $L$. tridentada diferencia-se da $L$. elliptica, a outra espécie coletada na ECFPn, por apresentar gametófitos menores $(2-3 \times 0,4-0,5 \mathrm{~mm})$, apenas dois ocelos, separados por3-4 células e anfigastros com lobos sempre eretos, enquanto $L$. elliptica apresenta gametófitos maiores (4-8x0,7-0,8mm), apesar de variar morfologicamente, sempre apresenta um ocelo basal e mais(1)2-3 ocelos laminares, o ocelo basal é separado do primeiro ocelo da lâmina por três células e os seguintes separados por uma célula e assim sucessivamente, anfigastros com lobos amplamente divergentes ou formando um sinus levemente convexo.

Material examinado: Melgaço (PA), ECFPn: margem esquerda do rio Curuá, várzea sobre folhas vivas, 2.XII.1997, A. L. Ilkiu-Borges, O. Nascimento \& M. Silva, 881; idem, 2.XII.1997, A. L. Ilkiu-Borges, O. Nascimento \& M. Silva, 883; idem, 8.XII.1997, A. L. Ilkiu-Borges, O. Nascimento \& M. Silva, 1134.

Rhaphidolejeunea polyrhiza (Nees) Bischler in Revue Briol. Lichenol., 36: 99. 1968 (Fig. 3).

Basiônimo: Lejeunea polyrhiza Nees in Gottsche, Lindenberg et Nees, Syn. Hep., 403. 1845. 
Tipo: Guiana Francesa. In folio Hirtellae americanae cum Lej. foliorum, s. d., s. col., s. n. (Lectótipo, STR; Isótipos, G, W).

Gametófitos

pequenos, amarelados, prostrados, $3-13 \mathrm{~mm}$ de comprimento e $0,3-0,4 \mathrm{~mm}$ de largura. Caulídio em secção transversal, 8 células epidérmicas circundando 4 células medulares menores, merófito ventral de duas células de largura. Filídios oblongos a elípticos, contíguos a sub-imbricados, $150-260 \mu \mathrm{m}$ de comprimento e $100-150 \mu \mathrm{m}$ de largura, ápice obtuso ou truncado a agudo, margens crenuladas a mais ou menos inteiras, 2-3 ocelos em série no lobo, em uma fila interrompida da base para o ápice do lobo, os ocelos supra-basais e os da porção mediana geralmente maiores que as células adjacentes (35$40 \times 20 \mu \mathrm{m} \quad$ e $30 \times 15 \mu \mathrm{m}$, respectivamente), o ocelo subapical pode estar ausente, com o mesmo tamanho das células adjacentes ou um pouco maior, células do lobo isodiamétrica-poligonais, $15-20 \mu \mathrm{m}$ as células da base mais alongadas, 20 -

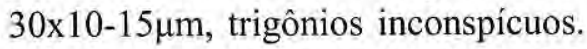
Lóbulos geralmente reduzidos a 6-7 células com uma papila apical, às vezes bem desenvolvidos, oblongos, inflados, $140 \mu \mathrm{m}$ de comprimento e $60 \mu \mathrm{m}$ de largura, quilha do lóbulo levemente arqueada, margem livre mais ou menos plana, dente apical formado por uma célula longa, fortemente falcada, quase encontra-se com a margem postical, papila hialina na base proximal do dente apical, células do lóbulo alongadas, dispostas lado a lado, na mesma direção da base para o ápice, no ápice forma-se uma boca lunulada, com 3-4 células conadas ao dente apical. Anfigastros pequenos, distantes, delgados, bífidos, com os lobos divergindo até formar uma linha horizontal ou levemente convexa, lobos filiformes com 2-3 células de comprimento, separados por duas células alongadas, na lâmina do lóbulo bordeada por seis células alongadas, 2 no ápice e 2 em cada lado, no centro encontram-se 5-10 pequenas células, $30-40 \mathrm{~mm}$ de comprimento e $60-80 \mathrm{~mm}$ de largura (140-200 mm, distância entre os ápices dos lobos), base acuneada. Androceu em pequenos ramos especializados, até 3 pares de brácteas, bractéolas somente na base da espiga. Gineceu em ramos especializados, com 1 inovação do tipo picnolejeuneóide, brácteas longoovaladas, ápice agudo, lóbulos largolanceolados, bractéola grande, bem maior que um anfigastro, bífida, largoobovada, cobrindo $1 / 2$ perianto ou um pouco menos, margens das brácteas e bractéolas irregulares, crenuladas com pequenos dentes ocasionais. Periantos obovados, inflados, com 5 quilhas, infladas, que se estendem para cima, formando pequenos cornos, ápices inteiros a crenulado-denticulados, 430 $500 \mathrm{~mm}$ de comprimento e $200-280 \mathrm{~mm}$ de largura, rostro pequeno, conspícuo. Esporófito não observado.

Distribuição geográfica: Distribuido pela América do Sul: Brasil, Guiana Francesa e Venezuela (Bischler, 1968), No Brasil é mencionada para os estados do AM e 

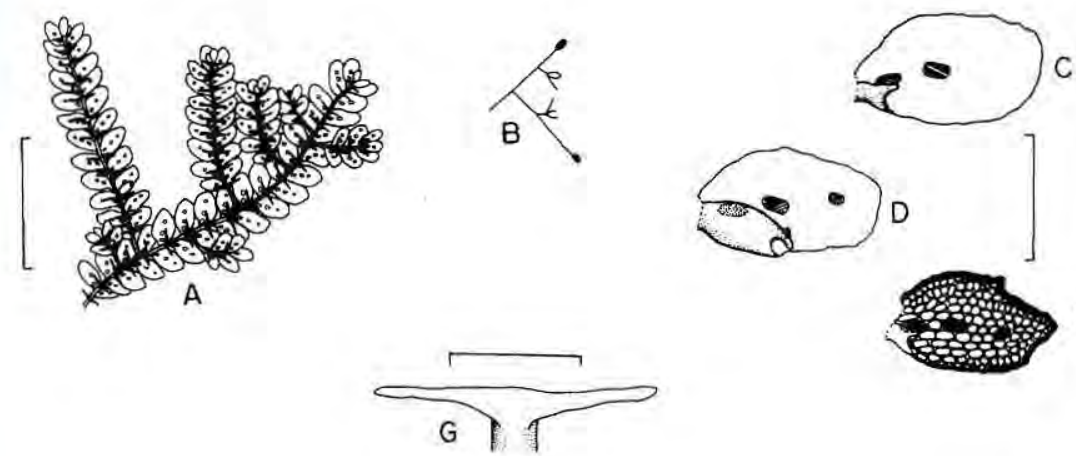

$E$
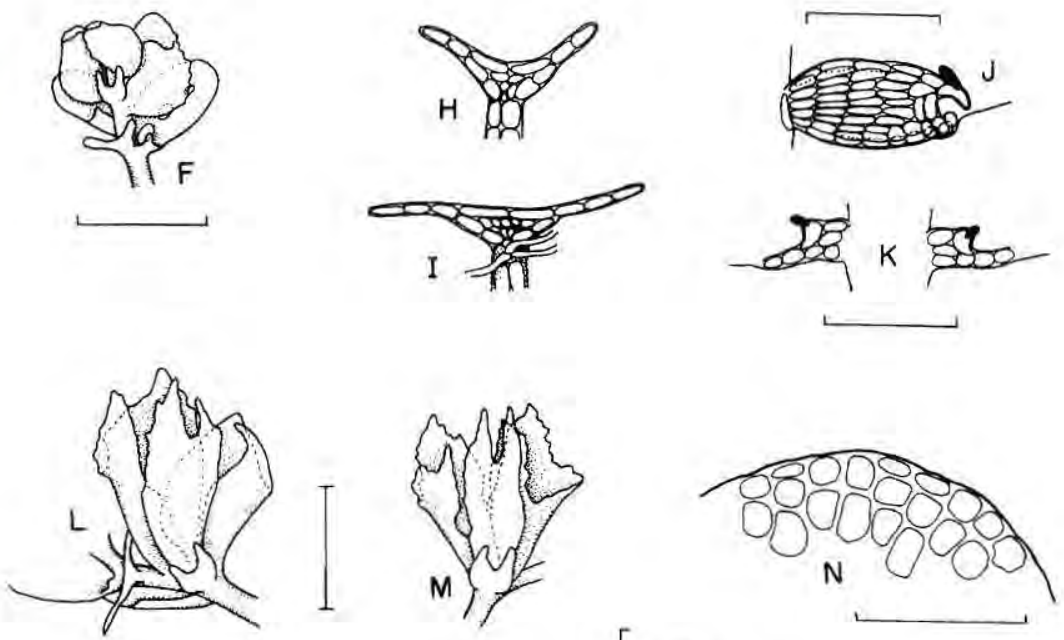

$\$$
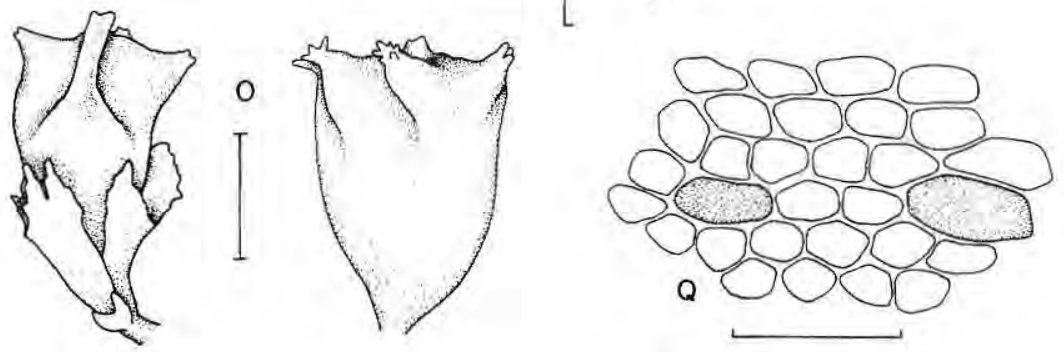

Figura 3. Rhaphidolejeunea polyrhiza (A-Q) A. hábito, vista ventral; B. esquema de planta fértil (o=perianto, $=$ androceu, E=gineceu); C, D e E. filidios; F. androceu; G, H e I. anfigastros; J. lóbulo desenvolvido; K. lóbulos reduzidos; L. gineceu, com inovação; M. gineceu; N. ápice do filídio; O. periantos; P. secção transversal do caulídio; Q. células da região mediana do filidio (A. L. Ilkiu-Borges, O. Nascimento \& M. Silva, 880); Escalas: A = Imm; C, D, E, F, L, M e $\mathrm{O}=200 \mathrm{~mm} ; \mathrm{G}, \mathrm{H}, \mathrm{I}, \mathrm{J}, \mathrm{K}$ e $\mathrm{P}=100 \mathrm{~mm} ; \mathrm{N}$ e $\mathrm{Q}=50 \mathrm{~mm}$ (Desenho: Anna Luiza Ilkiu-Borges). 
PA (Yano, 1948b; Bischler, 1968).

Discussão: Rhaphidolejeunea

é um gênero asiático-americano, sendo $R$. polyrhiza a única espécie a ocorrer na América (Bischler, 1968). É uma espécie exclusivamente epifila que cresce no sub-bosque de florestas úmidas e não perturbadas de acordo com Gradstein (comunicação pessoal, 1998). Esta espécie pode ser confundida com Leptolejeunea spp., pelo tamanho pequeno dos gametófitos, pelos ocelos em uma fila interrompida, pelos anfigastros com lobos filiformes, porém em $R$. polyrhiza, geralmente os lóbulos encontram-se reduzidos, quando desenvolvidos apresentam um longo dente em forma de gancho e nos anfigastros as células dos bordos não são tão grandes quanto em Leptolejeunea spp. E os lobos divergem até formar uma longa linha horizontal, as células do lobo apresentam trigônios e espessamentos intercelulares e no gineceu há geralmente uma inovação.

Material

examinado:

Município de Melgaço (PA), ECFPn: margem esquerda do Rio Curuá, várzea, sobre folhas vivas de Eugenia sp., 29.XI.1997, A. L. IlkiuBorges, O. Nascimento \& M. Silva, 874; idem, sobre folhas vivas de Aganisia sp. (Orchidaceae), 29.XI.1997, A. L. Ilkiu-Borges, O. Nascimento \& M. Silva, 876; idem sobre folhas vivas de epifita (Pteridófita), 29.XI.1997, A. L. IlkiuBorges, O. Nascimento \& M. Silva, 878; idem, mata de terra firme, sobre folhas vivas de Aspidosperma sp. (Apocynaceae), 2.XII.1997, A. L. IlkiuBorges, O. Nascimento \& M. Silva, 879; idem sobre folhas de Dodecastigma sp., 2.XII.1997, A. L. Ilkiu-Borges, O. Nascimento \& M. Silva, 880; idem sobre folhas vivas, 2.XII.1997, A. L. Ilkiu-Borges, O. Nascimento \& M. Silva, 881; idem, 2.XII.1997, A. L. IlkiuBorges, O. Nascimento \& M. Silva, 882; idem, 2.XII.1997, A. L. Ilkiu-Borges, O. Nascimento \& M. Silva, 883; idem, sobre folhas de planta jovem no subbosque, 5.XII.1997, A. L. Ilkiu-Borges, O. Nascimento \& M. Silva, 919; idem, várzea, sobre folhas de cipó, 8.XII.1997, A. L. Ilkiu-Borges, O. Nascimento \& M. Silva, 1052; idem, sobre folhas vivas, 8.XII.1997, A. L. Ilkiu-Borges, O. Nascimento \& M. Silva, 1080; idem, 2.XII.1997, A. L. Ilkiu-Borges, O. Nascimento \& M. Silva, 1107; idem, 2.XII.1997, A. L. Ilkiu-Borges, O. Nascimento \& M. Silva, 1134; idem, sobre folhas de planta jovem no subbosque, 2.XII.1997, A. L. Ilkiu-Borges, O. Nascimento \& M. Silva, 1147; igarapé Grande, várzea muito úmida sobre plântula viva e folhas, 17.1.1993, R. Lisboa 2310.

\section{Conclusões}

A espécie Leptolejeunea tridentata é mencionada pela primeira vez para o Brasil.

Entre as espécies de Leptolejeunea encontradas na Estação Científica Ferreira Penna, observa-se que o substrato mais utilizado foi o de folhas de plantas do sub-bosque de floresta primária. $L$. tridentata ocorreu exclusivamente sobre folhas, enquanto 
L. elliptica foi observada sete vezes como epífila e duas vezes como corticícola. Rhaphidolejeunea polyrhiza ocorreu somente sobre folhas vivas. Portanto, na ECFPn verificou-se preferência dos exemplares das espécies estudadas por folhas vivas, como substrato.

A espécie L. tridentata foi coletada somente no ecossistema de várzea, enquanto $L$. elliptica foi encontrada com a mesma freqüência tanto no ecossistema de várzea como no de terra firme e apenas uma vez no ecossistema de capoeira. Entretanto esta área de capoeira encontra-se em estágio avançado de regeneração e cercada de mata primária. A espécie Rhaphidolejeunea polyrhiza foi encontrada tanto na terra firme, quanto na várzea, mas com maior freqüência neste último ecossistema.

Verifica-se que essas espécies encontradas na Estação Científica Ferreira Penna são geralmente epífilas, com preferência por ambientes primários, confirmando a importância da preservação do ambiente onde ocorrem, como forma de manter sua existência.

\section{Bibliografia citada}

Bischler, H. 1968. Monographie du genre Rhaphidolejeunea Herzog. Revue Bryologique et Lichénologique, v. 36, p. 56-104.

Bischler, H. 1969. Le genre Leptolejeunea (Spruce) Steph.en Amerique. Nova Hedwigia, v. 17, p. 265-375.

Evans, A. W. 1902. Hepaticae of Puerto Rico.

I. The species of Leptolejeunea, including an account of their vegetative reproduction. Bull. Torrey bot. Club., v. 29, p. 496-510.
Lisboa, R. C. L. 1993. Musgos Acrocárpicos do Estado de Rondônia. Belém, Museu Paraense Emilio Goeldi, 272p.

Lisboa, R. C. L; Nazaré, J. M. M. de. 1997. A Flora Briológica. In: Lisboa, P. L. B. (Org.) Caxiuanã. Belém, Museu Paraense Emilio Goeldi, p. 221-233.

Lücking, A. 1995. Diversität und Mikrohabitatpräferenzen epiphyller Moose in einem tropichen Regenwald in Costa Rica. Ulm. 211p. Tese (Doutorado) Universidade de Ulm, Alemanha.

Iwatsuki, Z.; Vitt, D. H.; Gradstein, S. R. 1976. Bryological Herbaria. A guide to the Bryological Herbaria of the World. Bryophytorum Bibliotheca. Band 8. J. Cramer, Germany. p.1-114.

Robbins, R. G. 1952 Bryophyte Ecology of a dune area in New Zealand. Vegetatio, Acta Geobotanica, v.4, p. 1-31.

Spruce, R. 1985. Hepaticae of the Amazon and the Andes of Peru and Equador. Contr. $N$. Y. bot. Gdn., v. 15, p. 1-588, (reimpressão).

Stephani, F. 1890. Die Gattung Lejeunea in Herbarium Lindenberg. Hedwigia, v. 29, p.1-142.

Yano, O. 1984a. Briófitas. In: Fidalgo, O., Bononi, V. L. R. (Coord.). Técnicas de coleta, preservação e herborização de material botânico. São Paulo: Instituto de Botânica. 62p. (Manual 4).

Yano, O. 1984b. Checklist of Brazilian liverworts and hornworts. J. Hattori Bot. Lab., v. 56, p. $481-548$.

Yano, O. 1989. An additional checklist of Brazilian bryophytes. J. Hattori Bot. Lab., v. 66 , p. $371-434$.

Yano, O. 1995. A new additional checklist of Brazilian bryophytes. J. Hattori Bot. Lab., v. 78 , p. $137-182$.

Aceito para publicação em 23/04/2002 